\title{
Análise de dez anos da produção acadêmica divulgada nos estudos científicos publicados no congresso ANPCONT
}

\author{
Analysis of ten years of the academic production published in the scientific \\ studies published in the congress ANPCONT
}

\author{
Henrique César Melo Ribeiro' \\ Geovanna Karinna Magalhães Ribeiro²
}

\begin{abstract}
Resumo
O objetivo deste estudo foi analisar o perfil, as características e o comportamento da produção científica divulgada nos estudos publicados no Congresso Anpcont no período de 2007 a 2016. Metodologicamente, foram utilizadas as técnicas de análise bibliométrica e de rede social em 847 artigos publicados. Os principais resultados foram: Beuren, Frezatti, Teixeira, Espejo, Macedo, Rodrigues, Miranda, Cornachione Junior, Almeida e Sarlo Neto são os autores que se destacaram e que ficaram evidentes na proficuidade das publicações e nas centralidades de grau e de intermediação. No que se refere às instituições, versam-se: USP, UFMG, UFPB e a FURB, que ficaram em realce tanto na produção de artigos como também na degree e na betweeness. Em relação aos temas, ficaram em evidência: governança corporativa, gestão de custos, disclosure, contabilidade gerencial, investimento, processo orçamentário, gerenciamento de resultados, informação contábil, contabilidade internacional e gestão pública. Conclui-se, de maneira geral, o perfil, as características e o comportamento da produção científica evidenciada nos trabalhos publicados no Congresso Anpcont de 2007 a 2016, ao contemplar, no bojo deste estudo, dados e informações que ajudam a melhor atingir e abranger o avanço da área do conhecimento Contabilidade por meio de indicadores bibliométricos e sociométricos que vislumbram as colaborações entre os atores, que são primordiais para a difusão e socialização do saber científico mediante a publicação de temas incipientes, emergentes, em maturação e ou legitimados na literatura científica nacional. Tal fato contribui para melhor entender e conhecer o campo científico da Contabilidade, influenciando em sua compreensão, e impactando, posteriormente, em seu avanço na área do saber das Ciências Sociais Aplicadas, criando valor acadêmico na literatura científica e ajudando em sua evidenciação e crescimento, mediante os temas que fazem com que as Ciências Contábeis evoluam e se aperfeiçoem no panorama empresarial no Brasil.
\end{abstract}

Palavras-chave: Bibliometria; Congresso Anpcont; Produção científica; Rede social.

\begin{abstract}
The objective of this study was to analyze the profile, characteristics and behavior of the scientific production published in the studies published in the Anpcont Congress from 2007 to 2016. Methodologically, bibliometric and social network analysis techniques were used in 847 published articles. The main results were: Beuren, Frezatti, Teixeira, Espejo, Macedo, Rodrigues, Miranda, Cornachione Junior, Almeida and Sarlo Neto are the authors that stood out in this study and that were evident in the proficuity of the publications and the centralities of degree and intermediation. Institutions include: USP, UFMG, UFPB and FURB, which were highlighted both in the production of articles, as well as degree and in-between. Corporate governance, cost management, disclosure, management accounting, investment, budgeting, results management, accounting information, international accounting and public management were all highlighted. In general, the profile, characteristics and behavior of the scientific production evidenced in the papers published in the Anpcont Congress from 2007 to 2016 is concluded, considering in the bulge of this study data and information that help to better reach and cover the advancement of the area of knowledge Accounting through bibliometric and sociometric indicators that envisage the collaborations between the actors that are primordial for the diffusion and socialization of scientific knowledge, through the publication of insipient themes, emerging, maturing and / or legitimized in the national scientific literature. This fact contributes to a better understanding and knowledge of the scientific field of Accounting, influencing its understanding, and later impacting on its advance in the area of the knowledge of Applied Social Sciences, creating academic value in the scientific literature; and helping in its disclosure and growth, through the themes that make Accounting Sciences evolve and improve in the business landscape in Brazil.
\end{abstract}

Keywords: Bibliometrics; Anpcont Congress; Scientific production; Social network.

Pos doutorando em Administração pela Unifor, Doutor em Administração pela Uninove, Mestre em Administração pela Unifor, Graduado em Contabilidade pela UFPI. Professor Adjunto da UFPI, Campus Ministro Reis Velloso, Parnaíba-PI. Brasil. Afiliação: Universidade Federal do Piauí (UFPI), Campus Ministro Reis Velloso, Parnaíba-PI. Lattes: http://lattes.cnpq.br/4885629365119489 Email: hcmribeiro@hotmail.com

2 Brasil. Afiliação: Faculdade Maurício de Nassau (Parnaíba-PI). Email: hcmribeiro@gmail.com 


\section{Introdução}

A investigação das publicações acadêmicas é realizada mediante a mensuração da produção científica (Beuren \& Souza, 2008; Ribeiro \& Corrêa, 2013). Isto posto, entende-se que a análise da produção científica é preponderante para qualquer campo do conhecimento (Nascimento \& Beuren, 2011), pois proporciona um mapeamento do saber estabelecido (Nascimento, Junqueira \& Martins, 2010), o que está sendo feito e o que ainda é preciso fazer; possibilitando determinar (Schweitzer, 2010), por exemplo, a identificação de temas de pesquisa do campo do saber (Ribeiro, 2013), quais são os pesquisadores e instituições mais profícuas (Ribeiro, Costa \& Ferreira, 2014), quais os principais meios de evidenciação da informação e do conhecimento (Freire, 2006), contemplando as principais características das nuances que se fazem inerentes ao bojo da área da ciência investigada (Souza et al., 2013).

Dentre os meios de comunicação da informação e do conhecimento científico estão os periódicos e os eventos científicos (Camargo et al., 2013). No que se refere aos eventos científicos, considera-se que estes são espaços de interlocução entre pares, com discussões aprofundadas, norteadas com interações entre os participantes. Evidencia-se que esse debate é salutar, uma vez que todo texto publicado em anais de eventos científicos são textos em elaboração, mesmo que decorrente de pesquisas já finalizadas. Caracteristicamente, a partir das discussões e das críticas recebidas durante os congressos científicos, os pesquisadores terão contribuições plausíveis para desenvolver seu estudo e, posteriormente, submetê-lo a um periódico científico da área correspondente (Tesche \& Souza, 2016).

No Brasil, os eventos científicos mais bem-conceituados da área são: o Encontro Nacional de PósGraduação em Administração (Enanpad), o Congresso USP de Controladoria e Contabilidade, o Congresso Brasileiro de Custos (CBC) e o congresso promovido pela Anpcont (Espejo et al., 2013). Em relação ao Anpcont, este é promovido pela Associação Nacional de Programas de Pós-Graduação em Ciências Contábeis, objetivando a difusão e a socialização dos estudos no campo do conhecimento das Ciências Contábeis, sendo assim considerado como um dos principais eventos científicos da área que ocorrem anualmente no Brasil (De Luca et al., 2011).

O congresso Anpcont possuía quatro áreas temáticas principais até 2014, eram elas: i) Controladoria e Contabilidade Gerencial (CCG); ii) Contabilidade para Usuários Externos (CUE); iii) Educação e Pesquisa em Contabilidade (EPC); e iv) Mercados Financeiro, de Crédito e de Capitais (MFC) (Cosenza et al., 2016). Contudo, a partir de 2015, foi incluída a quinta área temática (v) Contabilidade Aplicada ao Setor Público e ao Terceiro Setor (CPT) (Anpcont, 2017).

Estudos focando a produção acadêmica dessas áreas temáticas da Anpcont já foram realizados e publicados. Seguem alguns destes: Souza et al. (2008), De Luca et al. (2011), Paula et al. (2012) e Cosenza et al. (2016). Apesar dos trabalhos enfatizarem com qualidade e destreza a produção científica do Congresso Anpcont em diversos períodos de tempo e sobre várias óticas, é necessário complementá-los e aperfeiçoálos mediante uma pesquisa que evidencie em seu bojo informações e conhecimentos contemporâneos sobre as áreas temáticas que compõem o Anpcont e, consequentemente sobre os autores, as instituições e as respectivas redes de atores e temas abordados e divulgados.

A questão de pesquisa que norteará este trabalho é: Qual o perfil, as características e o comportamento da produção científica divulgada nos estudos publicados no Congresso Anpcont de 2007 a 2016 ? Nesse sentido, tem-se por objetivo: analisar o perfil, as características e o comportamento da produção científica divulgada nos estudos publicados no Congresso Anpcont no período de 2007 a 2016. Contempla-se que uma das formas de analisar a produção científica é alicerçada pelas técnicas de análise bibliométrica (Cunha, Correa \& Beuren, 2010) e sociométrica (Ribeiro, 2015).

Justifica-se este estudo por possibilitar alcançar um maior entendimento e abrangência das informações, conhecimentos e saberes contemporâneos sob a ótica da Anpcont no período em análise da área das Ciências Contábeis, alicerçados e norteados pelas técnicas bibliométricas e sociométricas (Cardoso, Bernardino \& Pessoa Araújo, 2018), que também são de suma importância para se conseguir atingir os resultados e as contribuições desejados neste trabalho científico.

Outra justificativa interessante e que, de certa forma, é bem visível ao leitor uma visão macro do perfil, características e comportamento da produção científica objeto de estudo em dez anos de publicação, 
observando-se, assim, um número redondo das divulgações da Anpcont em suas respectivas quatro áreas temáticas, ou seja, i) Controladoria e Contabilidade Gerencial (CCG); ii) Contabilidade para Usuários Externos (CUE); iii) Educação e Pesquisa em Contabilidade (EPC); e iv) Mercados Financeiro, de Crédito e de Capitais (MFC).

Outra justificativa que se faz presente neste trabalho científico é evidenciar uma visão ampla das redes de colaboração e temas (embrionários, emergentes, maduros e legitimados) vislumbrados nos dez anos de publicação para servir de suporte, informação e conhecimento para os leitores, estudantes de stricto sensu ou lato sensu, professores, pesquisadores, simpatizantes à área de Contabilidade, colaboradores como os avaliadores ad hoc, editores do referido congresso científico. Possibilitando a posteriori que este estudo possa contribuir para fomentar a qualidade das publicações divulgadas no mencionado congresso, proporcionando a criação de novos congressos análogos a este e, fazendo surgir novas revistas científicas para a área em análise e afins.

E, por fim, uma justificativa também importante e que se faz necessária de enfatizar é buscar entender e compreender as nuances que alicerçam e norteiam o evento científico Anpcont, que, mesmo ainda novo, ou seja, com pouco tempo de vida, conseguiu difundir, disseminar e socializar, por meio de um heterogêneo e diversificado número de pesquisadores/professores de inúmeras instituições, uma variedade de temas que influencia e contribui para fomentar os conhecimentos e os saberes da área científica da Contabilidade. Realizar um estudo desse porte, enfatizando de maneira contemporânea e recente os atores envolvidos diretamente no aporte e fomento teórico como também das informações científicas que fazem enriquecer a área ora analisada, é uma oportunidade para observar a abrangência, envergadura e a relevância que esses atores e seus respectivos temas o são para a Contabilidade à luz da Anpcont.

Os indicadores bibliométricos e sociométricos mensurados neste estudo ajudarão a responder a questão de pesquisa e, com isso, as informações e os conhecimentos oriundos contribuirão para o melhor entendimento e compreensão da produção científica (Cardoso, Bernardino \& Pessoa Araújo, 2018) da Anpcont nos últimos dez anos, proporcionando o surgimento, aperfeiçoamento, maturação e/ou legitimação de estudos, sobretudo nas quatro áreas temáticas em destaque nesta pesquisa, impactando em uma maior difusão e socialização de temas, o que será feito mediante o alargamento e afloramento dos relacionamentos (conexões) entre os atores (autores e Instituições de Ensino Superior - IESs) que, porventura, venham a divulgar seus trabalhos no Congresso Anpcont, por meio das áreas temáticas que compõem esse evento científico.

Outra contribuição que alicerça e norteia este estudo é, efetivamente, por meio dos indicadores bibliométricos e sociométricos, possibilitar uma visão de dez anos de produção científica dos artigos divulgados na Anpcont. Tal fato é salutar, visto que os dados, informações, conhecimentos e saberes contemporâneos evidenciados neste estudo são preponderantes para alargar, abranger e difundir o entendimento e o compreendimento que a área de Ciências Contábeis têm para o processo de fomento e robustez da produção científica nacional, à luz de temas preponderantes e necessários para a criação de valor acadêmico e empresarial no Brasil.

\section{Produção acadêmica divulgada nos estudos científicos}

Os estudos científicos são as fontes basilares para o desenvolvimento e avanço do conhecimento (Judice \& Baêta, 2005), pois representam uma das formas de compreender determinados acontecimentos e circunstâncias e de apontar nortes, tendências e soluções. Ressalta-se que a sociedade como um todo pode ter informação desses estudos científicos mediante os anais de congressos e de publicações de artigos em periódicos científicos (Cunha, Correa \& Beuren, 2010), realçando que são os caminhos naturais da divulgação da produção acadêmica, que é preponderante para pesquisadores, docentes, estudantes e para as suas respectivas IES, (Ferreira \& Falaster, 2016).

A produção científica de uma determinada área do conhecimento reflete o seu estado da arte e seu crescimento (Leal, Almeida \& Bortolon, 2013). A publicação da produção científica é primordial para a difusão e socialização da atividade científica (Souza \& Ribeiro, 2013), uma vez que permite a soma dos esforços de 
múltiplos pesquisadores no aperfeiçoamento de um determinado campo do saber (Oliveira, 2002). Realçase que, para o desenvolvimento do conhecimento científico, é preponderante a manutenção e atuação de estudiosos nas áreas do saber (Beuren, Machado \& Vesco, 2015).

Versa-se que as pesquisas que enfocam a produção científica em Contabilidade no Brasil estão sendo cada vez mais comumente trabalhadas nos últimos anos (Souza, Silva \& Oliveira Araújo, 2013), em decorrência das mudanças econômicas e sociais, ao aumento dos cursos de pós-graduação na área (Vieira, Ensslin \& Silva, 2011) e de sua importância na evidenciação da comunicação, que é necessária para que se entendam as características (Dantas et al., 2011) e comportamentos de suas informações e conhecimentos, que são divulgados por meio de estudos científicos, impactando em sua produção acadêmica na literatura científica nacional (Borges, Faria \& Gil, 2007). Dentre esses estudos científicos incluem-se os trabalhos de artigos científicos (Leite Filho, 2010) de congressos científicos, como o caso da Anpcont (De Luca et al., 2011; Paula et al., 2012; Cosenza et al., 2016).

Posto isto, seguem alguns resultados e/ou conclusões de estudos (Figura 1) que versam sobre a produção científica em Contabilidade no Brasil. Ressalta-se que tais pesquisas são relevantes e essenciais para que se entenda e compreenda a dinâmica e a importância dessas investigações para o alargamento, a robustez e a difusão do conhecimento e, consequentemente, da ciência como um todo, sobretudo no que se refere às características e ao comportamento da Contabilidade nacional sob a ótica acadêmica. Salienta-se, com isso, que tais estudos ajudaram, também, de acordo com suas respectivas possibilidades, na discussão dos achados deste trabalho.

\begin{tabular}{|c|c|}
\hline Autores & Resultados/Conclusões \\
\hline $\begin{array}{l}\text { Theóphilo e } \\
\text { ludícibus (2005) }\end{array}$ & $\begin{array}{l}\text { Entenderam que a evolução da produção científica em Contabilidade se processa na } \\
\text { medida em que se busca, inspiração em uma maior diversidade de estratégias de pesquisa, } \\
\text { abordagens metodológicas e teóricas. }\end{array}$ \\
\hline $\begin{array}{l}\text { Cardosc } \\
(2005)\end{array}$ & $\begin{array}{l}\text { Verificaram que as instituições com maior número de publicações, em ordem decrescente, } \\
\text { foram a USP, FGV (SP), FGV (RJ) e UFRGS. São Paulo foi o estado com o maior número } \\
\text { de artigos publicados. }\end{array}$ \\
\hline $\begin{array}{l}\text { Leite Filho } \\
\text { (2008) }\end{array}$ & $\begin{array}{l}\text { Evidenciou uma padronização de publicação da área, indícios de forte endogenia de } \\
\text { instituições nacionais, existência de concentração de autoria vinculada a poucas instituições } \\
\text { que apresentaram as mais altas frequências relativas nos veículos de publicação, em } \\
\text { especial a USP, UnB, UFRJ, UFSC, UFPE e Fucape. }\end{array}$ \\
\hline $\begin{array}{l}\text { Souza } \\
(2008)\end{array}$ & $\begin{array}{l}\text { Constataram a existência de dois grupos predominantes com características análogas; } \\
\text { as IESs USP, UnB, Fucape e UFSC se destacam; as áreas temáticas 'Controladoria e } \\
\text { Contabilidade Gerencial' e 'Contabilidade para Usuários Externos' são predominantes entre } \\
\text { as IESs mais prolíficas, enquanto a área 'Educação e Pesquisa em Contabilidade' é a } \\
\text { menos explorada nas pesquisas. }\end{array}$ \\
\hline $\begin{array}{l}\text { Mendo } \\
\text { Riccio } \\
\text { (2009) }\end{array}$ & $\begin{array}{l}\text { Destacam as IESs USP, UNB/UFPB/UFPE/UFRN, FUCAPE, UFRJ e Unisinos. Cabe } \\
\text { observar que a FEA-USP responde individualmente por parte importante das participações } \\
\text { na produção da pesquisa em Contabilidade. Essa constatação não surpreende, uma vez } \\
\text { que o seu programa de pós-graduação em Contabilidade é o mais antigo em funcionamento } \\
\text { no país. }\end{array}$ \\
\hline $\begin{array}{l}\text { Cruz } \\
(201\end{array}$ & $\begin{array}{l}\text { Evidenciaram que parte dos atores ocupa posição privilegiada na estrutura da rede, } \\
\text { mostrando-se abertos a outros grupos e assumindo posições de pontes que ligaram } \\
\text { pesquisadores que não estariam conectados sem a sua presença. Em linhas gerais, o perfil } \\
\text { das redes de cooperação mostrou-se predominantemente caracterizado pela presença de } \\
\text { laços fortes. }\end{array}$ \\
\hline $\begin{array}{l}\text { De Luca et al. } \\
\text { (2011) }\end{array}$ & $\begin{array}{l}\text { Constataram que a participação feminina na produção científica contábil, é significativamente } \\
\text { pequena em relação à do gênero masculino, e que sua evolução relativa costuma } \\
\text { acompanhar a da quantidade total de autores, sendo que nos últimos anos assinalou uma } \\
\text { queda no tocante aos eventos da USP e da ANPAD, e um aumento no que tange ao da } \\
\text { Anpcont. }\end{array}$ \\
\hline
\end{tabular}




\begin{tabular}{|l|l|}
\hline $\begin{array}{l}\text { Paula et al. } \\
(2012)\end{array}$ & $\begin{array}{l}\text { Constataram que, nos Congressos Anpcont, a diversidade em termos de métodos, } \\
\text { paradigmas e temas foi fator determinante para o diálogo científico: as áreas temáticas que } \\
\text { apresentaram maior heterogeneidade naquelas classificações obtiveram maior quantidade } \\
\text { de artigos citados e vice-versa. }\end{array}$ \\
\hline $\begin{array}{l}\text { Silva et al. } \\
(2012)\end{array}$ & $\begin{array}{l}\text { Constataram que os programas da USP e da FURB possuem as maiores médias de } \\
\text { quantidade de atores; há uma tendência evolutiva dos programas Fucape, FURB, PUC } \\
\text { SP, UFba, UFPE, UFRJ, UFSC e Unisinos no que diz respeito à quantidade de vínculos } \\
\text { das redes de colaboração. Conclui-se que a maioria dos programas tem contribuído para } \\
\text { a evolução das pesquisas e publicações científicas na área contábil, e, para tanto, tem-se } \\
\text { utilizado parcerias colaborativas no desenvolvimento de suas pesquisas. }\end{array}$ \\
\hline $\begin{array}{l}\text { Cosenza et al. } \\
(2016)\end{array}$ & $\begin{array}{l}\text { Apontam que os Congressos Anpcont tendem a reproduzir conhecimento vigente, } \\
\text { propagando pesquisas que reforçam a abordagem contábil predominante, o que pode } \\
\text { representar um projeto pedagógico de ensino-aprendizagem que dissemina um modelo } \\
\text { homogêneo de pensamento contábil ancorado no emprego de princípios, métodos e } \\
\text { técnicas que preservam o status quo, e replica o que já está dado como paradigma de } \\
\text { pesquisa. }\end{array}$ \\
\hline $\begin{array}{l}\text { Pedroni et al. } \\
(2016)\end{array}$ & $\begin{array}{l}\text { Concluíram que os resultados apresentados são de particular relevância para acadêmica } \\
\text { da área de Contabilidade, pois brindam uma imagem aproximada do quadro geral em que } \\
\text { as investigações específicas devem ser integradas. }\end{array}$ \\
\hline
\end{tabular}

Figura 1: Pesquisas sobre a produção científica em Contabilidade.

Fonte: Dados da pesquisa.

Os estudos evidenciados aqui manifestam dados e informações diversas que interagem, de maneira robusta e alargada, no bojo e em todas as nuances, no que se refere à produção científica em Contabilidade no Brasil, adentrando nas características, particularidades e no comportamento do citado tema sob a ótica de pesquisas acadêmicas publicadas em congressos e em revistas científicas.

Entretanto, no que se refere aos eventos científicos, foco predominante deste estudo, em especial ao Congresso Anpcont, ressalva-se que foi explorado de maneira macro em poucos estudos, ou seja, não contemplando informações e conhecimentos específicos de uma determinada área do mencionado evento, mas, sim, no que tange ao saber científico divulgado como um todo, por meio de seus estudos científicos, e categorizado por suas áreas temáticas em conjunto, sobretudo aquelas que estão presentes desde o nascimento do referido congresso científico.

Nesse sentido, coloca-se a contribuição, importância e justificativa de se realizar este trabalho, tendo em vista que evidenciará dados e informações contemporâneos à luz das técnicas de análise bibliométrica e sociométrica, proporcionando elencar conhecimentos e saberes sobre a produção científica da pesquisa em Contabilidade no Brasil sob a ótica do Congresso Anpcont.

Esse painel proporcionará que as informações e os conhecimentos vistos por meio das investigações divulgadas no citado congresso sejam conhecidos, influenciando e contribuindo para o fomento e a difusão do entendimento e compreensão da área do conhecimento Contabilidade, contribuindo para: o alargamento de estudos científicos sobre esse campo do saber; a criação de novos estudos e grupos de pesquisa; e o surgimento de novos meios de comunicação e difusão do conhecimento científico, como o caso dos eventos e periódicos científicos.

Em suma, o estudo do perfil, das características e do comportamento da produção científica divulgada nos estudos publicados no Congresso Anpcont, de 2007 a 2016, justifica-se pelo necessário aperfeiçoamento continuado das Ciências Contábeis no Brasil. Em outras palavras, para acompanhar o desenvolvimento da sociedade, de maneira a atender e atingir suas constantes mutações e inovações de demanda (Ferrari et al., 2012), faz-se necessária e prudente a realização desta pesquisa em âmbito nacional.

\section{Procedimentos metodológicos}

O objetivo deste estudo foi analisar o perfil, as características e o comportamento da produção científica divulgada nos estudos publicados no Congresso Anpcont no período de 2007 a 2016. Ressalta-se que uma 
das formas de avaliar e mensurar a produção científica é com base nas técnicas de análise bibliométrica (Cunha, Correa \& Beuren, 2010) e de rede social (Parreiras et al., 2006). Pesquisadores da bibliometria desenvolveram e criaram "leis" particulares para a análise da produção científica (Cardoso et al., 2005).

As leis bibliométricas mais frequentemente usadas são: lei de Lotka, relacionada à produtividade científica dos autores; lei de Bradford, que se relaciona à dispersão da produção científica dos periódicos científicos; e lei de Zipf, que mensura a ocorrência de palavras no texto científico. Essas leis são estruturadas em corpo teórico que justifica o status de ciência ao conjunto de informações que então se configurava em torno do objeto conhecimento (Bufrem \& Prates, 2005).

Já a rede social é entendida como um grupo de atores e as suas possíveis e respectivas interações, evidenciando como pontos principais: (i) atores ou nós, que são os indivíduos que participam da rede; (ii) laços, que concebem as conexões entre atores; (iii) nós isolados, que versam na produção científica isolada dos estudos; (iv) relação, sendo o tipo de informação e conhecimento trocado em um laço; (v) reciprocidade, que são as interações que ocorrem nos dois sentidos; e (vi) tamanho da rede, que compreende o número de conexões existentes entre os atores (Rosa et al., 2010). Também as redes sociais podem ser agrupadas em propriedades estruturais, como as medidas de densidade e centralidade (Rossoni, Hocayen-da-Silva \& Ferreira Júnior, 2008). A densidade é o grau de acuidade da relação dos atores da rede social e, com sua aferição, contribui-se para a formulação de conjecturas sobre as informações e conhecimentos que circundam pela rede social (Mello, Crubellate \& Rossoni, 2010).

Já a centralidade é empregada frequentemente e envolve características relacionadas à importância ou visibilidade de um ator em uma rede social (Cruz et al., 2011), podendo ser classificada em centralidade de grau (degree), centralidade de intermediação (betweeness) e centralidade de proximidade (closeness) (Bordin, Gonçalves \& Todesco, 2014). Dentre essas proxies, as mais habitualmente utilizadas são a centralidade de grau e a centralidade de intermediação (Mendes-da-Silva, Onusic \& Giglio, 2013). Aquela é alcançada a partir do número de amarrações diretas que um ator possui e a esta considera se um ator assume, ou não, atitude de intermediador na rede (Cruz et al., 2011). Nesta pesquisa, serão enfatizadas as seguintes estruturas de rede: densidade, centralidade de grau e de centralidade de intermediação (Mello, Crubellate \& Rossoni, 2010).

Foi realizada uma de artigos divulgados no período de 2007 a 2016, o que corresponde a um levantamento longitudinal de 10 anos. Os dados foram coletados da Associação Nacional de Programas de Pós-Graduação em Ciências Contábeis (http://www.anpcont.org.br/congressos-anpcont). Os estudos abrangidos foram retirados das quatro áreas temáticas principais da Anpcont, são elas: i) Controladoria e Contabilidade Gerencial (CCG); ii) Contabilidade para Usuários Externos (CUE); iii) Educação e Pesquisa em Contabilidade (EPC); e iv) Mercados Financeiro, de Crédito e de Capitais (MFC) (Cosenza, Paula, Laurencel \& Barreto, 2016). Esse processo admitiu identificar 246 artigos da área CCG, 294 estudos da área CUE, 151 trabalhos da área EPC e 156 investigações da área MFC. No total, foram 847 publicações analisadas. Foi realizada a análise dos dados por meio dos seguintes indicadores: (I) autores mais profícuos por área temática; (II) redes de coautoria por área temática; (III) IES mais produtivas por área temática; (IV) redes sociais das IES por área temática; e (V) temas mais abordados por área temática. Esses indicadores foram calculados e capturados utilizando os softwares UCINET ${ }^{\circledR}$, versão 6.0, e Microsoft Excel ${ }^{\circledR}$, versão 2007. E a visualização das figuras das redes sociais foram feitas mediante o software NetDraw.

\section{Análise e discussão dos resultados}

A Figura 2 evidencia os autores mais profícuos por área temática da Anpcont. Ilse Maria Beuren e Carlos Eduardo Facin Lavarda foram os autores com maior destaque na área temática CCG. Já na área temática CUE, afloram os pesquisadores: Fernando Dal-Ri Murcia, Marcelo Alvaro da Silva Macedo e Roberto Carlos Klann. No que se refere à área temática EPC, destacam-se os acadêmicos Gilberto José Miranda e Edvalda Araújo Leal. Os estudiosos Alfredo Sarlo Neto, Bruno Funchal e Márcio André Veras Machado ficam em evidência na área temática MFC. Dos 48 autores em foco na Figura 2, ficam em evidência llse Maria Beuren e Márcio André Veras Machado como os que mais publicaram, ambos com 15 estudos. As divulgações de Beuren, I. M. se manifestam somente na área temática CCG, entretanto as publicações de Machado, M. A. 
V., estão distribuídas nas áreas temáticas CUE e MFC. Salientam-se, também, os acadêmicos: Espejo, M. M. dos S. B., Costa, F. M. da, Paulo, E., Colauto, R. D., Martinez, A. L., e Rodrigues, A., que tiveram realce em mais de uma área temática.

É importante ressaltar e reiterar que somente estão contemplados nesta seção os autores que obtiveram maior proficuidade nas respectivas áreas temáticas em investigação do Congresso Anpcont. Tal explicação é necessária, em razão de que a quantidade de pesquisadores identificados, envolvidos e que publicaram estudos nas quatro áreas temáticas da Anpcont, de 2007 a 2016, é superior ao que é vislumbrado na Figura 2, contudo, por questão de organização, espaço e, sobretudo, pela quantidade de autores, entendeu-se ser coerente apenas ressalvar e realçar os estudiosos mais profícuos de cada área temática, perfazendo um total de 48.

Agora, indo ao encontro da lei de Lotka, a qual enfatiza a produtividade dos autores (Cardoso et al., 2005), constata-se que, em todas as áreas temáticas da Figura 2, poucos autores costumam publicar muito e muitos pesquisadores divulgam em quantidade menor suas publicações, indo ao encontro do que a lei de Lotka enfatiza (Ribeiro \& Tavares, 2017). Os estudos de Cardoso et al. (2005), Leite Filho(2008), Mendonça Neto, Riccio \& Sakata (2009) corroboram com os achados realçados nesta seção.

Os achados visualizados nesta seção ajudam a entender e compreender a importância e a envergadura desses estudiosos para o aperfeiçoamento, desenvolvimento, fomento, difusão e disseminação dos conhecimentos científicos inerentes de maneira respectiva às quatro áreas temáticas envolvidas na investigação, contribuindo para agregar valor acadêmico e robustez ao campo das Ciências Contábeis, impactando em sua produção científica no âmbito do cenário acadêmico e literário nacional, sob a ótica do Congresso Anpcont.

\begin{tabular}{|c|c|c|c|c|c|c|c|}
\hline \multicolumn{8}{|c|}{ Áreas Temáticas } \\
\hline \multicolumn{2}{|l|}{ CCG } & \multicolumn{2}{|l|}{ CUE } & \multicolumn{2}{|l|}{ EPC } & \multicolumn{2}{|l|}{ MFC } \\
\hline Autores & $\begin{array}{c}\text { Artig } \\
\text { os }\end{array}$ & Autores & $\begin{array}{l}\text { Artig } \\
\text { os }\end{array}$ & Autores & $\begin{array}{l}\text { Artig } \\
\text { os }\end{array}$ & Autores & $\begin{array}{c}\text { Artig } \\
\text { os }\end{array}$ \\
\hline Beuren, I. M. & 15 & Murcia, F. D. R. & 8 & Miranda, G. J. & 13 & Sarlo Neto, A. & 12 \\
\hline Lavarda, C. E. F. & 11 & $\begin{array}{l}\text { Macedo, M. A. } \\
\text { da S. }\end{array}$ & 8 & Leal, E. A. & 10 & Funchal, B. & 8 \\
\hline Aguiar, A. B. de & 9 & Klann, R. C. & 8 & $\begin{array}{l}\text { Espejo, M. M. dos } \\
\text { S. B. }\end{array}$ & 7 & $\begin{array}{l}\text { Machado, M. } \\
\text { A. V. }\end{array}$ & 8 \\
\hline Diehl, C. A. & 9 & Paulo, E. & 7 & $\begin{array}{l}\text { Cornachione Junior, } \\
\text { E. B. }\end{array}$ & 5 & Galdi, F. C. & 6 \\
\hline Frezatti, F. & 9 & Costa, F. M. da & 7 & $\begin{array}{l}\text { Alves da Cunha, J. } \\
\text { V. A. da }\end{array}$ & 5 & $\begin{array}{l}\text { Almeida, J. E. } \\
\text { F. de }\end{array}$ & 6 \\
\hline Teixeira, A. J. C. & 7 & $\begin{array}{l}\text { Machado, M. A. } \\
\text { V. }\end{array}$ & 7 & $\begin{array}{l}\text { Castro Casa Nova, } \\
\text { S.P. de }\end{array}$ & 4 & $\begin{array}{l}\text { Costa, F. M. } \\
\text { da }\end{array}$ & 5 \\
\hline Souza, M. A. de & 7 & $\begin{array}{l}\text { Coutinho e } \\
\text { Silva, A. H. }\end{array}$ & 6 & $\begin{array}{l}\text { Domingues, M. J. } \\
\text { C. de S. }\end{array}$ & 4 & $\begin{array}{l}\text { Cunha, M. F. } \\
\text { da }\end{array}$ & 5 \\
\hline Lunkes, R. J. & 7 & Rodrigues, A. & 6 & & & Rodrigues, A. & 4 \\
\hline Borgert, A. & 6 & Martinez, A. L. & 6 & & & $\begin{array}{l}\text { Martinez, A. } \\
\text { L. }\end{array}$ & 4 \\
\hline $\begin{array}{l}\text { Oyadomari, J. C. } \\
\text { T. }\end{array}$ & 6 & Santos, A. dos & 6 & & & Paulo, E. & 4 \\
\hline $\begin{array}{l}\text { Marquezan, L. H. } \\
\text { F. }\end{array}$ & 6 & Kronbauer, C. A. & 6 & & & $\begin{array}{l}\text { Bortolon, P. } \\
\text { M. }\end{array}$ & 4 \\
\hline $\begin{array}{l}\text { Espejo, M. M. } \\
\text { dos S. B. }\end{array}$ & 6 & Ribeiro, M. de S. & 6 & & & Colauto, R. D. & 4 \\
\hline $\begin{array}{l}\text { Cesar, A. M. R. } \\
\text { V.C. }\end{array}$ & 5 & $\begin{array}{l}\text { De Luca, M. M. } \\
\text { M. }\end{array}$ & 6 & & & $\begin{array}{l}\text { Lamounier, } \\
\text { W. M. }\end{array}$ & 4 \\
\hline Fernandes, F. C. & 5 & Cunha, P. R. da & 6 & & & & \\
\hline $\begin{array}{l}\text { Almeida, L. B. } \\
\text { de }\end{array}$ & 5 & Colauto, R. D. & 6 & & & & \\
\hline Silva, M. Z. da & 5 & & & & & & \\
\hline Guerreiro, R. & 5 & & & & & & \\
\hline Cardoso, R. L. & 5 & & & & & & \\
\hline Nossa, V. & 5 & & & & & & \\
\hline Santos, V. dos & 5 & & & & & & \\
\hline
\end{tabular}

Figura 2: Autores mais profícuos por área temática

Fonte: Dados da pesquisa 
Constata-se que o estudo de redes de coautoria é um tipo de rede social alicerçada na análise de colaboração entre unidades de pesquisa, podendo ser constituída por autores e suas respectivas instituições (Cardoso, Bernardino \& Pessoa Araújo, 2018). Isto posto, a Figura 3 visualiza as quatro redes de coautoria por área temática, enfatizando o degree de cada uma delas. Analisando a Figura 3, contemplam-se as seguintes densidades por área temática: $C C G=0,0069$, CUE $=0,0060, E P C=0,0093$ e MFC =0,0101. Fazendo uma comparação entre essas densidades, observa-se que todas são bastante análogas. Entendese que, em todas as redes de coautoria vislumbradas, as suas respectivas interações entre os autores estão aquém da normalidade, ou seja, observa-se que as possíveis conexões entre os pesquisadores estão entre $0,60 \%$ na CUE e $1,01 \%$ na MFC, o que nos faz entender e compreender que o relacionamento entre esses estudiosos é incipiente.

Essa pouca interação entre os acadêmicos pode ocorrer em razão: (i) da pouca vida do Congresso Anpcont na literatura acadêmica nacional; (ii) em decorrência de poucos grupos de pesquisa que interagem no congresso publicando seus respectivos achados; (iii) da existência de grupos de investigação já consolidados, influenciando as divulgações dessas investigações somente nesses grupos e impactando na pouca densidade da rede; e (iv) pela ocorrência da alta centralidade dos autores (Cruz et al., 2011), contribuindo para uma fraca densidade na rede.

Em relação à centralidade dos estudiosos, em especial ao degree, têm-se na área temática CCG: Fábio Frezatti, Ilse Maria Beuren, Carlos Eduardo Facin Lavarda, Rogério João Lunkes, Aridelmo José Campanharo, Carlos Alberto Diehl e Marcos Antonio de Souza. Na área temática CUE: Clóvis Antônio Kronbauer, Marcelo Alvaro da Silva Macedo, Edilson Paulo, Adriano Rodrigues, Márcia Martins Mendes De Luca, Romualdo Douglas Colauto e Marcelle Colares Oliveira. Já os pesquisadores: Gilberto José Miranda, Márcia Maria dos Santos Bortolocci Espejo, Edvalda Araújo Leal e Edgard Bruno Cornachione Junior se destacam na área temática EPC. E no MFC estão os acadêmicos: Alfredo Sarlo Neto, José Elias Feres de Almeida, Patrícia Maria Bortolon, Bruno Funchal e Fernando Caio Galdi.

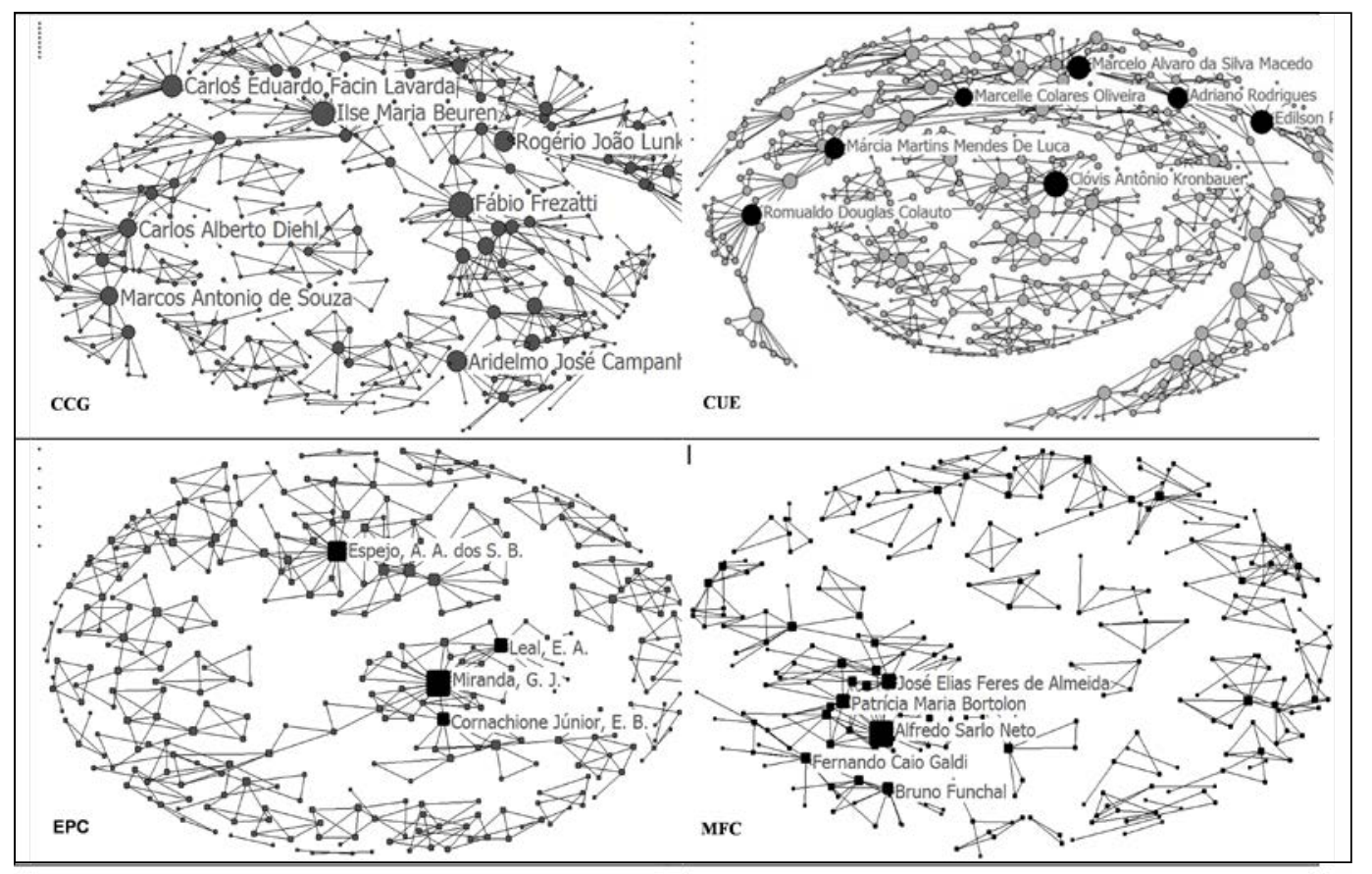

Figura 3: Redes de coautoria (degree) por área temática: CCG, CUE, EPC e MFC Fonte: Dados da pesquisa

É interessante notar que grande parte dos investigadores em ênfase nesta seção também aparecem como os mais profícuos (Figura 2) em suas respectivas áreas temáticas, ressalvando, cada um, sua importância, envergadura e contribuição na construção, desenvolvimento, evidenciação e disseminação da informação e dos saberes científicos na Contabilidade no Brasil. 
Já a Figura 4 é análoga à Figura 3, contudo, enfoca a centralidade de intermediação dos autores por área temática. Observando a Figura 4, citam-se como autores mais centrais no que tange a betweenness na área temática CCG: Fábio Frezatti, Ilse Maria Beuren, Franciele Beck, Emanuel R. Junqueira e Francisco Carlos Fernandes. Na área temática CUE surgem os acadêmicos: Alexsandro Broedel Lopes, Fernando Dal-Ri Murcia, Marcelo Alvaro da Silva Macedo, Aridelmo José Campanharo Teixeira, Adriano Rodrigues, Ariovaldo dos Santos e Adolfo Henrique Coutinho e Silva. Já na área temática EPC aparecem os estudiosos: Márcia Maria dos Santos Bortolocci Espejo, Gilberto José Miranda, Silvana Anita Walter e Edgard Bruno Cornachione Junior. E, por fim, os pesquisadores José Elias Feres de Almeida, Alfredo Sarlo Neto, Eliseu Martins, Luiz João Corrar e Moisés Ferreira da Cunha têm as maiores centralidades de intermediação na área temática MFC.

É importante notar que, entre os estudiosos evidenciados como mais centrais neste estudo, alguns destacam-se tanto na centralidade de grau como na de intermediação. Por área temática, são eles: CCG Fábio Frezatti, Ilse Maria Beuren; CUE - Marcelo Alvaro da Silva Macedo, Adriano Rodrigues; EPC - Márcia Maria dos Santos Bortolocci Espejo, Gilberto José Miranda, Edgard Bruno Cornachione Junior; MFC - José Elias Feres de Almeida, Alfredo Sarlo Neto. Porém somente Aridelmo José Campanharo Teixeira ficou em evidência em duas áreas temáticas, ou seja, como um dos mais centrais na degree na área temática CCG e na betweenness na área temática CUE.

Ainda cabe reiterar que os autores Ilse Maria Beuren, Fábio Frezatti, Aridelmo José Campanharo Teixeira, Márcia Maria dos Santos Bortolocci Espejo, Marcelo Alvaro da Silva Macedo, Adriano Rodrigues, Gilberto José Miranda, Edgard Bruno Cornachione Junior, José Elias Feres de Almeida e Alfredo Sarlo Neto, além de se destacarem na centralidade de grau e de intermediação, também ficam em ênfase na produtividade de artigos. Dentre eles, enfocam-se os estudiosos Márcia Maria dos Santos Bortolocci Espejo e Adriano Rodrigues, que ficaram em evidência em duas áreas temáticas.

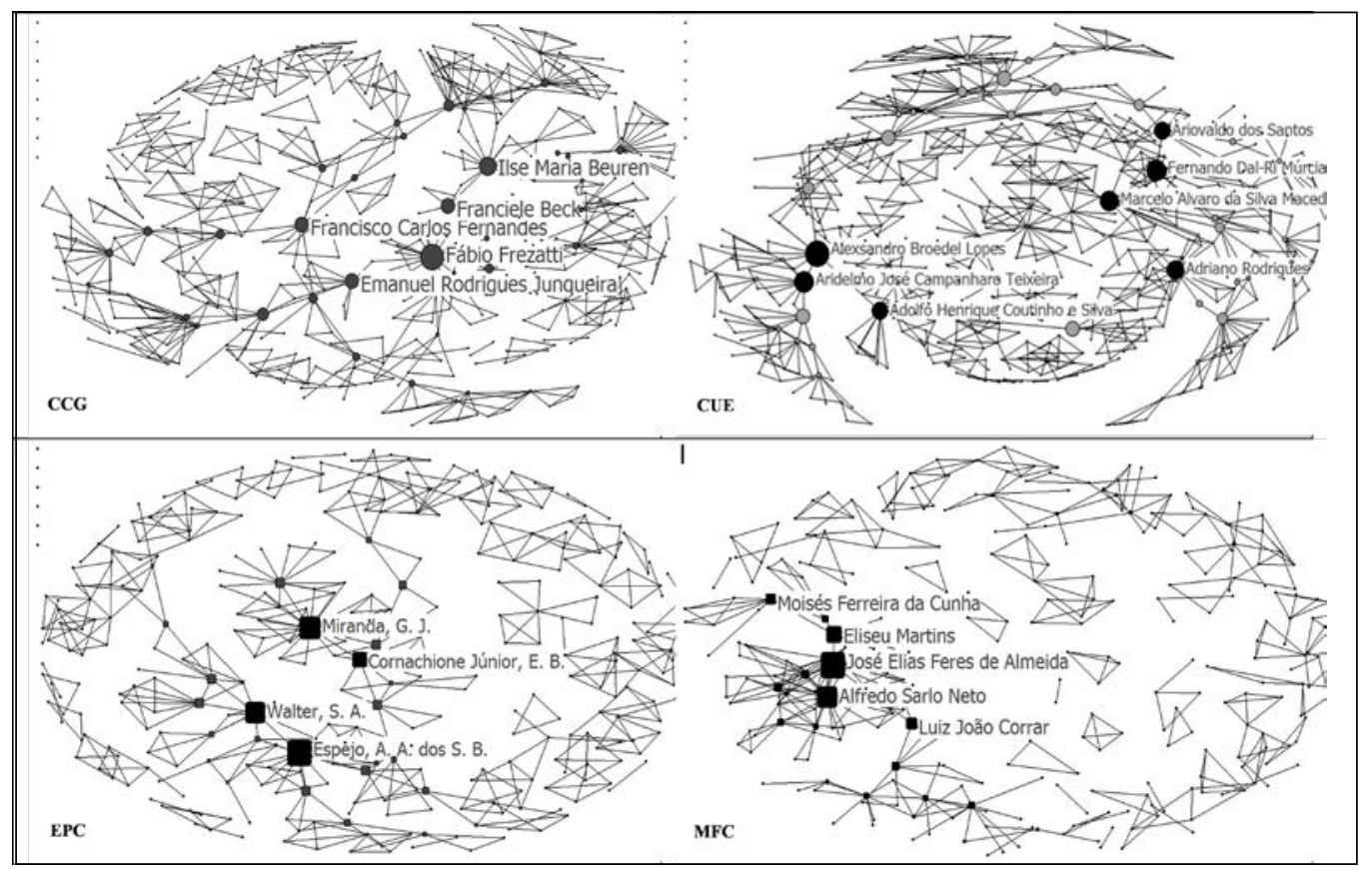

Figura 4: Redes de coautoria (betweenness) por área temática: CCG, CUE, EPC e MFC Fonte: Dados da pesquisa

A autora Espejo, em realce na CCG e na EPC, e o investigador Rodrigues, que ficou em realce na área temática CUE e na MFC, também se destacam. Os acadêmicos vislumbrados nesta seção, em especial neste parágrafo, são os mais importantes, representativos e relevantes na produção científica dos estudos divulgados nas áreas temáticas objeto de estudo do Congresso Anpcont, de 2007 a 2016, influenciando, a posteriori, no crescimento, na difusão e na socialização da informação e do conhecimento científico na área de Contabilidade no contexto nacional por meio de suas respectivas IES. 
A Figura 5 contempla as IES mais produtivas por área temática. É importante ressaltar que a quantificação dos artigos para cada IES foi realizada tendo por base a mensuração desses artigos para os autores. Em outras palavras, o vínculo da produção científica de cada IES foi realizado mediante o link atual do autor no instante em que o mesmo publicou seu estudo em uma das áreas temáticas da Anpcont evidenciadas neste estudo. Por exemplo: a autora Ilse Maria Beuren influenciou na produção científica das FURB, da UFPR e da UFSC, pois a referida pesquisadora, no ato das publicações dos seus respectivos estudos, possuía vínculo com a FURB ou com a UFPR ou com a UFSC. Salienta-se que, atualmente, a citada pesquisa é oriunda da UFSC.

A Figura 5 mostra que a FURB e a USP ficaram em evidência na área temática CCG; já na área temática CUE, a USP e a Fucape se destacaram. Na EPC, realçam-se as instituições USP e UFU. ePor fim, a MFC enfatiza as instituições Fucape e UFPB. Fazendo uma breve análise somente com esses dados vistos neste parágrafo, a USP ficou em relevo em três das quatro áreas temáticas analisadas neste estudo, o que nos faz entender e compreender sua relevância e importância para a produção científica dos estudos divulgados na Anpcont no período de 2007 a 2016, fato que influencia na informação e no conhecimento manifestado nas Ciências Contábeis na literatura acadêmica brasileira (Mendonça Neto, Riccio \& Sakata, 2009) à luz do mencionado congresso.

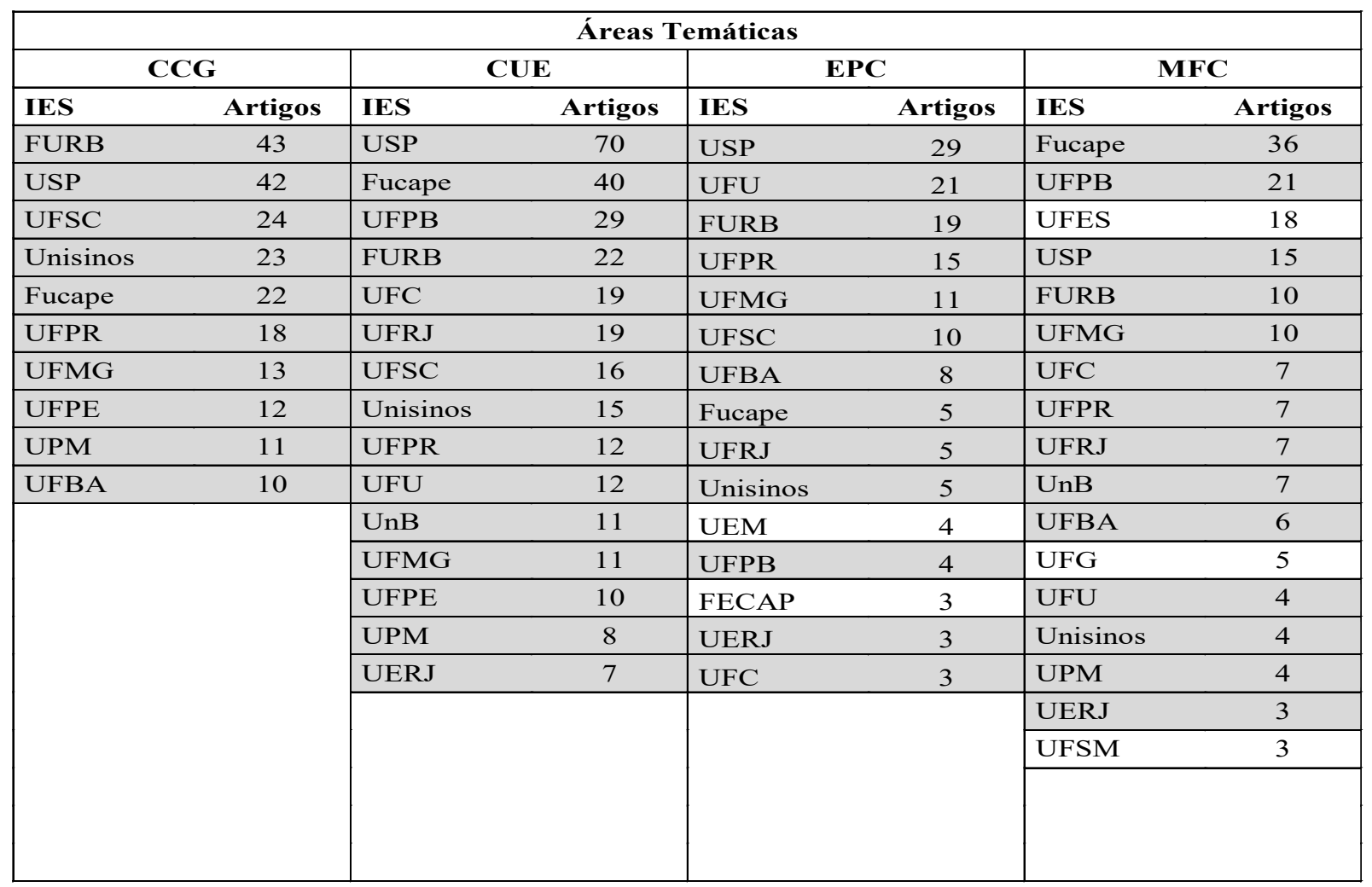

Figura 5: IES mais produtivas por área temática

Fonte: Dados da pesquisa

Das 21 IES contempladas na Figura 5, que ficaram em destaque por área temática, somente a USP e a Fucape conseguiram publicar mais de uma centena de artigos cada, ou seja, 156 e 103, respectivamente, o que mostra suas respectivas envergadura e relevância na produção científica de temas relacionados à Contabilidade sob a ótica da Anpcont. Em seguida, versam-se sobre as seguintes instituições: FURB, UFPB, UFPR e UFSC, com 94, 54, 52 e 50 divulgações, respectivamente, no total das áreas temáticas. É importante ressaltar também que as IES Unisinos, UFMG, UFU e UFRJ, tiveram 47, 45, 37 e 31 publicações respectivas cada.

Diante do contexto, e observando tais instituições, é possível constatar, pelo menos para este estudo que contempla as quatro áreas temáticas que mais divulgaram artigos na Anpcont, que essas IES são as mais representativas no âmbito acadêmico nacional, propiciando o alargamento e a robustez da área 
do conhecimento da Contabilidade no panorama nacional. Esses achados são corroborados por estudos similares: Cardoso et al., (2005), Leite Filho (2008), Souza et al., (2008), Mendonça Neto, Riccio e Sakata (2009) e Silva et al., (2012).

Os resultados vistos nesta seção explicam a incidência e a constância dessas instituições no painel acadêmico nacional contábil, criando, com isso, valor científico, que, por sua vez, contribui e proporciona ucrescimento, aperfeiçoamento, otimização, evidenciação, disseminação e socialização das informações e do conhecimento manifestado por meio dos estudos acadêmicos divulgados no Congresso Anpcont. Contribuindo, também, para o entendimento e a compreensão de como essas instituições interagem entre si por meio de suas respectivas redes sociais.

No panorama das instituições de ensino superior, a visualização e o entendimento das redes sociais tem se tornado preponderante, visto que a academia tem como alguns dos produtos finais as teses, as dissertações e os artigos científicos a posteriori, sendo que estes últimos, em especial, são formas de se compreender e avançar o conhecimento, na grande parte das vezes, de maneira colaborativa (Cardoso, Bernardino \& Pessoa Araújo, 2018), e as instituições têm papel ímpar para o alargamento, difusão e socialização desse conhecimento (Rossoni, Hocayen-da-Silva \& Ferreira Júnior, 2008).

Posto isto, a Figura 6 concebe as quatro redes sociais das IES por área temática, sublinhando, contudo, a centralidade de grau de cada uma delas. Como ocorrerá e observada nas redes de coautoria (Figuras 3 e 4), as redes sociais das instituições envolvidas e identificadas neste estudo também apresentam pouca densidade, isto é, as redes sociais das IES da área temática CCG têm uma densidade de 0,0366; as redes sociais das instituições da CUE versam uma densidade de 0,0421; adensidade das redes das IES da área temática EPC é de 0,0341; e a densidade das instituições da MFC é de 0,0447.

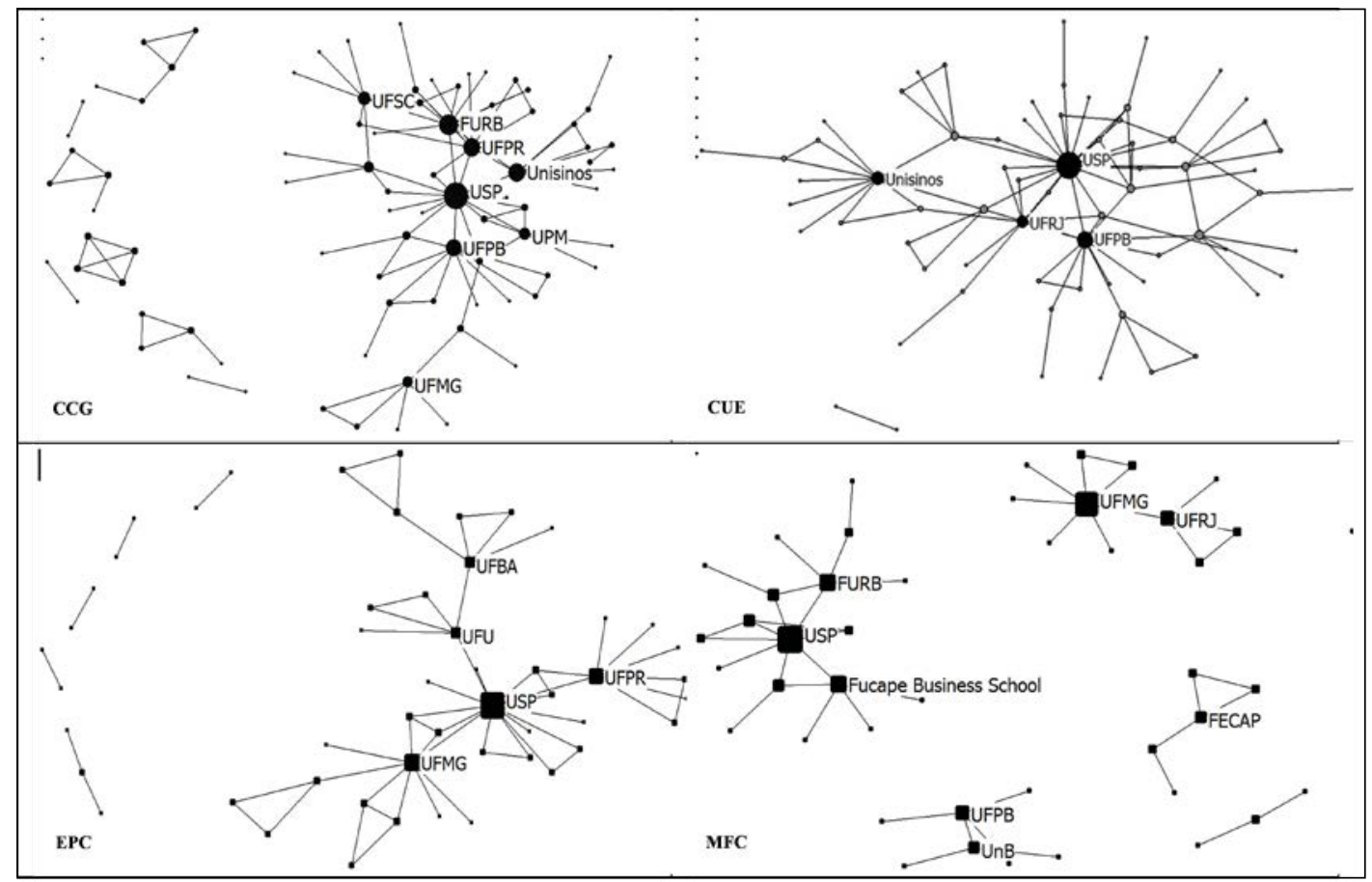

Figura 6: Redes sociais das IES (degree) por área temática: CCG, CUE, EPC e MFC

Fonte: Dados da pesquisa

Esses resultados podem ser consequência: (i) da baixa densidade das redes de coautoria; (ii) dos programas de pesquisas já consolidados existentes (Souza et al., 2008; Silva et al., 2012), dificultando a entrada de novos autores, e, logo, de novas instituições; (iii) da pouca idade do Congresso Anpcont no panorama científico contábil nacional; (iv) da alta centralidade de algumas instituições (Leite Filho, 2008), deixando a produção científica, de certa forma, concentrada em poucos grupos de estudo; e (v) do alto agrupamento da produção acadêmica divulgada na Anpcont nas regiões Sudeste e Sul do Brasil. Informações 
que podem dar sinais de uma elite de autores e IES possuidoras dos maiores percentuais de publicação na área de Contabilidade no Brasil (Leite Filho, 2008).

Em relação à centralidade de grau, a Figura 6 emerge as seguintes instituições por área temática: USP, FURB, Unisinos, UFPR, UFPB, UFSC, UPM e UFMG na área temática CCG; na CUE, têm-se as instituições: USP, UFPB, Unisinos e UFRJ; na área temática EPC, destacam-se: USP, UFMG, UFPR, UFU e Ufba; e, na MFC, realçam-se as instituições de ensino: Fucape, UFPB, USP, FURB, UFMG, UFRJ, UnB e Fecap.

Fazendo uma comparação e uma analogia entre as quatro áreas temáticas, constata-se que a USP é a única que aparece com relevo em todas as áreas, confirmando sua relevância, importância e contribuição na produção científica, por área temática, das investigações divulgadas na Anpcont de 2007 a 2016 . Além da USP, podem ser ressalvadas também as instituições: UFPB e UFMG que aparecem em relevo, no que se refere ao degree, em três áreas temáticas. Tal achado contribui para reiterar e ratificar as instituições aqui manifestadas como as mais representativas e com maior envergadura no contexto científico nacional, no que se refere a produções científicas de estudos no campo do saber contabilidade, em especial a USP.

Já a Figura 7 é similar a Figura 6, entretanto focaliza a centralidade de intermediação das IES por área temática. Na área temática CCG, as instituições com maior centralidade de intermediação são: USP, FURB, Unisinos, UFPB, FGV (SP), UFPR, Ufes e UFMG. Na CUE enfatizam-se as IES: USP, UFPB, Unisinos e UnB; enquanto na área temática EPC estão as instituições de ensino: USP, UFMG, UFPR, UFU e Ufba. Por fim, as IES Fucape, USP, FURB, UFMG e UFRJ, que se destacam na centralidade de intermediação na MFC.

Agora, trazendo os achados das instituições com maior degree, constata-se que USP, FURB, Unisinos, UFPB, UFPR e UFMG destacam-se tanto na centralidade de grau como também na de intermediação na área temática CCG. No que se refere à área CUE, têm-se as instituições USP, UFPB e Unisinos, que se realçam em ambas as centralidades. Na EPC aparecem em foco as IES: USP, UFMG, UFPR, UFU e Ufba. Na MFC estão as instituições de ensino: Fucape, USP, FURB, UFMG e UFRJ.

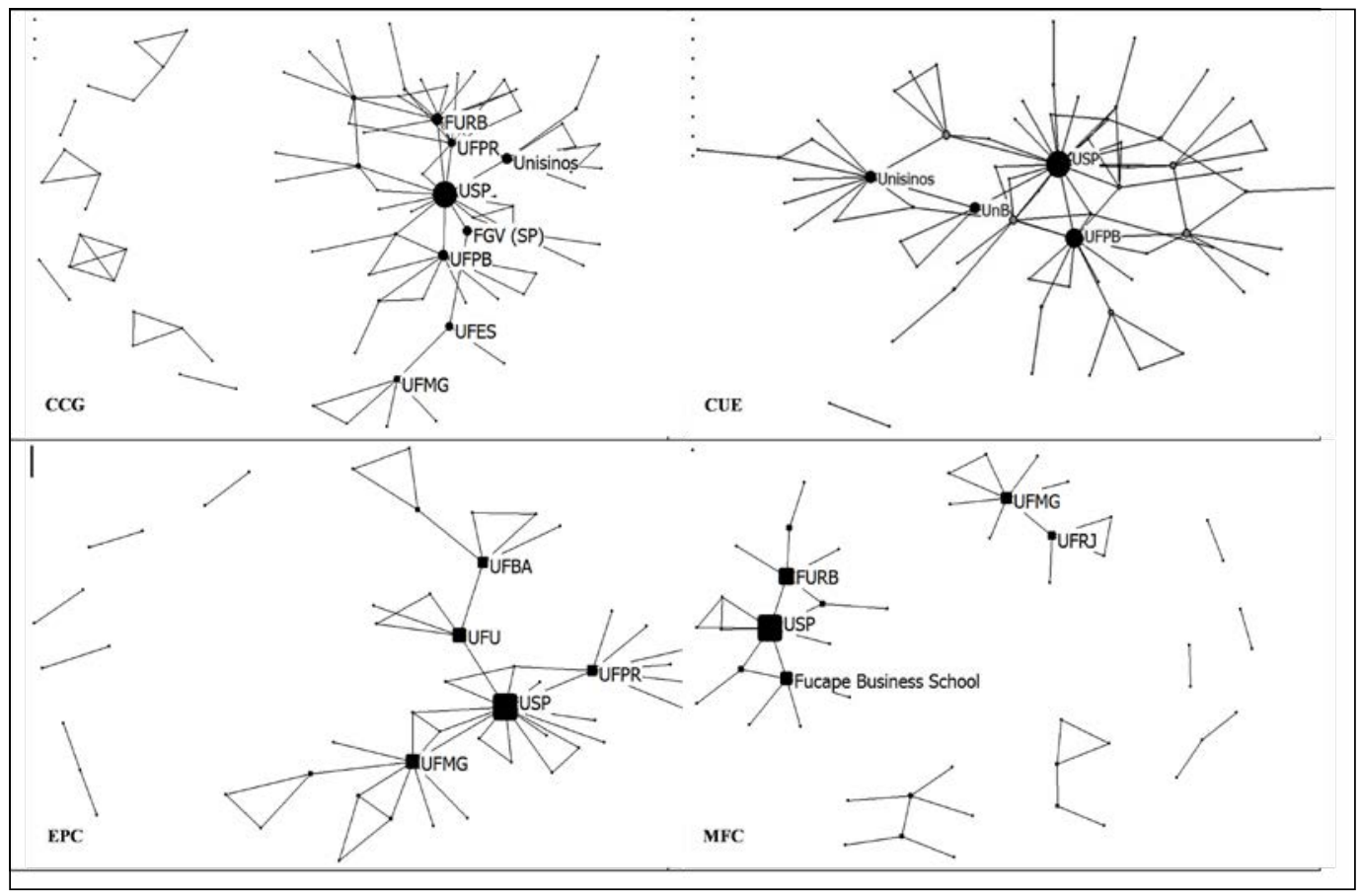

Figura 7: Redes sociais das IESs (betweenness) por área temática: CCG, CUE, EPC e MFC Fonte: Dados da pesquisa

Fazendo um resumo das instituições que ficaram em evidência neste trabalho, ou seja, que se destacaram tanto na proficuidade como também nas respectivas centralidades aqui analisadas, surgem USP, UFMG, UFPB e FURB como as mais importantes e proeminentes para a compreensão, o avanço e contribuição da produção científica dos estudos divulgados na Anpcont de 2007 a 2016. Tal afirmação é justificada em decorrência dessas IES conseguirem permear, alicerçar e nortear, em todos os níveis de análise 
aferidos nesta investigação, em outras palavras, na produtividade de artigos, e também como instituições com maior centralidade de grau e de intermediação. Tal resultado é corroborado, de maneira análoga por outros trabalhos: Cardoso et al., (2005), Leite Filho (2008), Souza et al., (2008), Mendonça Neto, Riccio e Sakata (2009), Silva et al., (2012).

A Figura 8, que mostra uma diversidade de temas (Paula et al., 2012), traz os mais abordados por área temática da Anpcont de 2007 a 2016, e alguns considerados tópicos quentes, ou seja, temas de fronteira (Ribeiro \& Corrêa, 2013). Analisando de maneira macro a Figura 8, constata-se o destaque dado ao tema governança corporativa, que ficou em realce em três das quatro áreas temáticas investigadas neste estudo (CCG, CUE e MFC). A área MFC ficou em primeiro lugar. As 47 publicações do tema governança corporativa, neste estudo, mostram sua maturidade e legitimidade manifestada na literatura acadêmica nacional (Ribeiro \& Santos, 2015). É possível interpretar que existe uma relação intrínseca entre governança corporativa e contabilidade (Lopes, 2004).

\begin{tabular}{|c|c|c|c|c|c|c|c|}
\hline \multicolumn{8}{|c|}{ Áreas Temáticas } \\
\hline \multicolumn{2}{|l|}{ CCG } & \multicolumn{2}{|l|}{ CUE } & \multicolumn{2}{|l|}{ EPC } & \multicolumn{2}{|l|}{ MFC } \\
\hline Temas & $\begin{array}{l}\text { Art } \\
\text { igos }\end{array}$ & Temas & $\begin{array}{l}\text { Art } \\
\text { igos }\end{array}$ & Temas & $\begin{array}{l}\text { Art } \\
\text { igos }\end{array}$ & Temas & $\begin{array}{l}\text { Art } \\
\text { igos }\end{array}$ \\
\hline $\begin{array}{l}\text { Gestão de } \\
\text { custos }\end{array}$ & 34 & $\begin{array}{l}\text { Gerenciamento de } \\
\text { resultados }\end{array}$ & 16 & Profissional contábil & 10 & $\begin{array}{l}\text { Governança } \\
\text { corporativa }\end{array}$ & 25 \\
\hline $\begin{array}{l}\text { Processo } \\
\text { orçamentári } \\
\text { o }\end{array}$ & 24 & $\begin{array}{l}\text { Normas } \\
\text { internacionais de } \\
\text { contabilidade }\end{array}$ & 15 & $\begin{array}{l}\text { Curso de ciências } \\
\text { contábeis }\end{array}$ & 9 & Investimento & 13 \\
\hline $\begin{array}{l}\text { Contabilida } \\
\text { de gerencial }\end{array}$ & 22 & Disclosure & 14 & Pesquisa em contabilidade & 8 & $\begin{array}{l}\text { Informação } \\
\text { contábil }\end{array}$ & 8 \\
\hline $\begin{array}{l}\text { Controladori } \\
\mathrm{a}\end{array}$ & 13 & $\begin{array}{l}\text { Governança } \\
\text { corporativa }\end{array}$ & 14 & Professor & 8 & $\begin{array}{l}\text { Gerenciamento } \\
\text { de resultados }\end{array}$ & 7 \\
\hline $\begin{array}{l}\text { Controle } \\
\text { gerencial }\end{array}$ & 13 & Informação contábil & 14 & Contabilidade gerencial & 7 & Auditoria & 6 \\
\hline $\begin{array}{l}\text { Balanced } \\
\text { Scorecard }\end{array}$ & 11 & Investimento & 11 & $\begin{array}{l}\text { Contabilidade } \\
\text { internacional } \\
\end{array}$ & 7 & $\begin{array}{l}\text { Estrutura de } \\
\text { capital }\end{array}$ & 6 \\
\hline $\begin{array}{l}\text { Gestão } \\
\text { pública }\end{array}$ & 11 & Auditoria & 10 & Ensino da contabilidade & 7 & Gestão de risco & 6 \\
\hline $\begin{array}{l}\text { Governança } \\
\text { corporativa }\end{array}$ & 8 & $\begin{array}{l}\text { Disclosure } \\
\text { voluntário }\end{array}$ & 10 & Desempenho acadêmico & 6 & $\begin{array}{l}\text { Mercado } \\
\text { corporativo }\end{array}$ & 6 \\
\hline & & Gestão pública & 10 & Produção científica & 5 & $\begin{array}{l}\text { Retorno das } \\
\text { ações }\end{array}$ & 6 \\
\hline & & $\begin{array}{l}\text { Disclosure } \\
\text { ambiental }\end{array}$ & 9 & $\begin{array}{l}\text { Programas de pós- } \\
\text { graduação em ciências } \\
\text { contábeis }\end{array}$ & 5 & $\begin{array}{l}\text { Avaliação de } \\
\text { empresas }\end{array}$ & 5 \\
\hline
\end{tabular}

Figura 8: Temas mais abordados por área temática.

Fonte: Dados da pesquisa.

Em seguida, aparece a temática gestão de custos com 34 estudos divulgados, porém, ao contrário do tema governança corporativa, que se fez presente em três das quatro áreas temáticas, a gestão de custos só ficou em evidência na área CCG. Mesmo assim, o suficiente para estar em segundo lugar na classificação geral dentre os temas mais abordados. Seu realce ocorre em consequência de sua importância fundamental no controle gerencial e nas tomadas de decisão (Bitti, Aquino \& Cardoso, 2011) para a área na qual ficou em foco (Ribeiro \& Corrêa, 2017).

O assunto disclosure ficou em evidência também neste trabalho, com 33 publicações, cabendo destacar que apareceu como somente disclosure, disclosure voluntário e disclosure ambiental apenas na área temática CUE. Optou-se em chamar exclusivamente de disclosure para facilitar, assim, sua análise e discussão. Seu relevo nesta investigação pode ser em decorrência de sua relação direta com o tema governança corporativa, sendo um dos fundamentais princípios que norteiam o referido tema (Malacrida \& Yamamoto, 2006), com predomínio para a mitigação da assimetria informacional (Castro Junior, Conceição \& Santos, 2011).

O tema contabilidade gerencial se fez presente em duas áreas temáticas, CCG e EPC, influenciando em seu destaque, com 29 investigações evidenciadas. Salienta-se que sua importância e relevância não 
estão apenas no meio acadêmico nacional (Ribeiro \& Corrêa, 2017), mas também no tocante ao âmbito científico internacional (Ribeiro \& Tavares, 2017), impactando diretamente em sua evolução como tema no mercado corporativo global (Beuren \& Erfurth, 2010). Em seguida, surge o tema investimento, que ficou em realce em duas áreas temáticas (CUE e MFC) impactando na sua publicação em 24 artigos.

Com a mesma quantidade de publicações, surge a temática processo orçamentário, contudo ficou em foco apenas na área temática CCG. Ressalta-se que o processo orçamentário é uma das temáticas mais estudadas pela literatura científica nacional na área contábil, pois praticamente todos os aspectos da contabilidade gerencial e controladoria estão integrados a essa temática, tais como a gestão de custos (Aguiar \& Souza, 2010).

O gerenciamento de resultados também aparece como um dos temas mais publicados, ficando em foco em duas áreas temáticas (CUE e MFC). Justifica-se sua relevância, pois é considerado um problema de pesquisa muito suscitado na academia (Baptista, 2009), com salutar destaque em pesquisas desenvolvidas na área contábil (Silva et al., 2015), sobretudo relacionando-se com o tema governança corporativa (Erfurth \& Bezerra, 2013).

Outro tema que ficou em proeminência foi a informação contábil, nas áreas temáticas CUE e MFC, totalizando 22 publicações. Sua ênfase deve-se ao fato de sua intrínseca relação e forte importância para a área contábil, como um todo, ou seja, está presente no bojo e nas nuances das informações, influenciando diretamente no processo decisório e nas tomadas de decisão dos gestores das empresas (Aquino \& Santana, 1992). É importante ressalvar que as normas internacionais de Contabilidade foram positivas para o maior desenvolvimento da qualidade da informação contábil (Coelho, Niyama \& Rodrigues, 2011).

As normas internacionais de contabilidade/contabilidade internacional também ficaram ressaltadas nesta investigação, com 22 estudos divulgados. $O$ destaque do mencionado tema pode ser explicado em razão de seu crescimento nas publicações, sobretudo em periódicos das áreas contábil e afins na literatura acadêmica nacional, influenciando diretamente na heterogeneidade de temáticas que se conectam diretamente com as normas internacionais de contabilidade/contabilidade internacional, dentre os quais citam-se: informação contábil, disclosure e gerenciamento de resultados (Ribeiro, 2014).

Aborda-se também o tema gestão pública, que ficou em foco neste estudo, aparecendo em realce nas áreas temáticas CCG e CUE. Isto posto, salienta-se o trabalho dos autores Fadul et al. (2014), que descreveram e analisaram a produção acadêmica do tema administração pública a partir do trabalho do Comitê Científico de Administração Pública da ANPAD no quadriênio 2009-12. Observaram avanços quantitativos na produção acadêmica da área de gestão pública ao longo da última década. Tal resultado vai ao encontro do que foi encontrado neste estudo.

\section{Considerações finais}

O objetivo desta investigação foi analisar o perfil, as características e o comportamento da produção científica divulgada nos estudos publicados no Congresso Anpcont no período de 2007 a 2016. Metodologicamente, foram empregadas as técnicas de análise bibliométrica e sociométrica em 847 artigos publicados.

Os resultados divulgados neste trabalho ajudam a visualizar como o panorama da produção científica da área contábil é difundido, disseminado e socializado na literatura científica nacional à luz do Congresso Anpcont. Esses achados são importantes para observar as nuances do processo acadêmico e da criação de valor científico por parte dos autores e de suas respectivas IES para o campo do saber Contabilidade, sendo impreterível e salutar as informações e os conhecimentos manifestados por esses pesquisadores, que impactam no alargamento e robustez de temas nativos e/ou que se relacionam, direta ou indiretamente, com a área contábil. Além disso, impactam também em sua própria evolução e maior compreensão e avanço no bojo acadêmico nacional.

Enfatiza-se que os dados, as informações e os conhecimentos manifestados nesta investigação, além de colaborarem para entender como a produção acadêmica da área contábil está sendo difundida no meio científico contábil nacional, influenciando em sua compreensão e avanço, serve também para que os 
próprios stakeholders do Congresso Anpcont constatem como esse congresso contribui para a robustecer deste campo do saber, enriquecendo, norteando e alicerçando todas as nuances que cercam e embasam as Ciências Contábeis no Brasil, em especial no que se refere aos temas que cooperam fortemente para isso.

Posto isto, constata-se que os saberes mensurados, evidenciados e disseminados neste estudo proporcionam, de maneira alargada e robusta, um entendimento e compreensão do perfil, das características e do comportamento da produção científica ora analisada, cooperando para se saber como a Contabilidade, à luz da Anpcont, é realçada e cria valor científico, influenciando consequentemente para seu avanço em suas nuances e em seu bojo na literatura acadêmica nacional.

Uma das contribuições deste estudo é proporcionar à sociedade acadêmica de Contabilidade brasileira a oportunidade de refletir acerca do norte que vem sendo dado à pesquisa nesse campo do saber, analisando o quadro apresentado por meio da produção científica dos estudos divulgados nos Congressos Anpcont de 2007 a 2016. Realça-se que o citado congresso vislumbra uma imagem análoga do que é visualizado no cenário das publicações acerca da área do conhecimento contábil no Brasil (Pedroni et al., 2016), contribuindo para um saber mais abrangente dos fenômenos estudados no referido campo do conhecimento (Theóphilo \& ludícibus, 2005).

Proporcionando, assim, sua melhor compreensão e posterior avanço no campo científico nacional, por meio de temas que surgem como tópicos quentes e temáticas maduras ou legitimadas, colaborando, a posteriori, para engrandecer e enriquecer o campo das Ciências Contábeis no Brasil e até, de certa forma, possibilitar o surgimento de novos congressos científicos para a área. Concomitantemente, criar novos periódicos científicos ou, até mesmo, aperfeiçoar os já existentes, impactando diretamente no seu Qualis Capes e em seu fator de impacto.

Este estudo limitou-se em analisar a produção científica do Congresso Anpcont, contudo é importante enfatizar que tanto a questão de pesquisa como também o objetivo do estudo foi respondido e alcançado, respectivamente. Entretanto é coerente dizer que todas as pesquisas científicas podem ser aperfeiçoadas, replicando-as. Versam-se algumas sugestões para estudos futuros: (i) realizar uma análise da produção científica da área contábil, comparando-a sob a ótica de dois ou mais congressos científicos da área, podendo ser no âmbito nacional como também internacional; (ii) alargar os indicadores bibliométricos e sociométricos, fazendo com que revelem novos dados e informações; (iii) discutir melhor os temas abordados e identificados neste trabalho, em busca de um melhor entendimento e compreensão.

\section{Referências}

Aguiar, A. B., \& Souza, S. M. de. Processo orçamentário e criação de reservas em uma instituição hospitalar. Revista Contemporânea de Contabilidade, 1(13), 107-126.

A.Anpcont - Associação Nacional de Programas de Pós-Graduação em Ciências Contábeis. Temas. Recuperado em: <http://congressos.anpcont.org.br/>.

Aquino, W., \& Santana, A. C. (1992). Evidenciação. Caderno de Estudos, (5), 1-40.

Baptista, E. M. B. (2009). Ganhos em transparência versus novos instrumentos de manipulação: o paradoxo das modificações trazidas pela lei $n^{\circ}$ 11.638. RAE, 49(2), 234-239.

Beuren, I. M., \& Erfurth, A. E. (2010). Pesquisa em contabilidade gerencial com base no futuro realizada no Brasil. Contabilidade, Gestão e Governança, 13(1), 44-58.

Beuren, I. M., Machado, D. G., \& Vesco, D. G. D. (2015). Análise sociométrica e bibliométrica de pesquisas publicadas no Management Accounting Research. CGG, 18(1), 83-105.

Beuren, I. M., \& Souza, J. C. (2008). Em busca de um delineamento de proposta para classificação dos periódicos internacionais de contabilidade para o qualis Capes. Revista Contabilidade \& Finanças, 19(46), 44-58.

Bitti, E. J. S., Aquino, A. C. B. de, \& Cardoso, R. L. (2011). Adoção de sistemas de custos no setor público: reflexões sobre a literatura nacional veiculada em periódicos acadêmicos. Revista Universo Contábil, 
7(3), 06-24.

Bordin, A. S., Gonçalves, A. L., \& Todesco, J. L. (2014). Análise da colaboração científica departamental através de redes de coautoria. Perspectivas em Ciência da Informação, 19(2).

Borges, T. N., Faria, A. C., \& Gil, A. L. (2007). Ensaio teórico sobre os fatores críticos de sucesso e pontos de falha do processo de gestão dos mestrandos em contabilidade: a ótica da metodologia DEQ. Revista de Educação e Pesquisa em Contabilidade, 1(3), 63-82.

Bufrem, L., \& Prates, Y. (2005). O saber científico registrado e as práticas de mensuração da informação. Ciência da Informação, 34(2), 9-25.

Camargo, R. V. W. (2013). Produção científica em auditoria: uma análise dos estudos acadêmicos desenvolvidos no Brasil. Contabilidade Vista \& Revista, 24(1), 84-111.

Cardoso, R. L., (2005). Pesquisa científica em contabilidade entre 1990 e 2003. Revista de Administração de Empresas, 45(2), 34-45.

Castro Junior, F. H. F., Conceição, P. M. de, \& Santos, D. A. (2011). A relação entre o nível voluntário de transparência e o custo de capital próprio das empresas brasileiras não financeiras. Revista Eletrônica de Administração, 17(3), 617-635.

Coelho, C. M. P., Niyama, J. K., \& Rodrigues, J. M. (2011). Análise da qualidade da informação contábil frente a implementação dos IFRS: uma pesquisa baseada nos periódicos internacionais (1999 a 2010). Sociedade, Contabilidade e Gestão, 6(2), 7-20.

Cosenza, J. P., (2016). Análise das características e similaridades presentes na produção científica dos congressos Anpcont 2007-2014. RCC, 13(28), 19-56.

Cruz, A. P. C. da, (2011). Perfil das redes de cooperação científica: congresso USP de controladoria e contabilidade - 2001 a 2009. Revista Contabilidade \& Finanças, 22(55), 64-87.

Cunha, P. R., Correa, D. C., \& Beuren, I. M. (2010). Assuntos de auditoria publicados nos periódicos nacionais e internacionais de contabilidade listados no qualis Capes. Revista de Informação Contábil, 4(1), 57-75.

Dantas, J. A., (2011). Padrões de comunicação científica em contabilidade: um comparativo entre a Revista Contabilidade e Finanças e a The Accounting Review. Revista Contemporânea de Contabilidade, 8(16), 11-36.

De Luca, M. M. M., (2011). Participação feminina na produção científica em contabilidade publicada nos anais dos eventos Enanpad, Congresso USP de Controladoria e Contabilidade e Congresso Anpcont. Revista de Contabilidade e Organizações, 5(11), 145-164.

Erfurth, A, E., \& Bezerra, F. A. (2013). Gerenciamento de resultados nos diferentes níveis de governança corporativa. Revista de Administração e Contabilidade da Unisinos, 10(1), 32-42.

Espejo, M. M. S. B., 2013). O mercado acadêmico contábil brasileiro: uma análise do cenário a partir das práticas de publicação e avaliação por pares. RUC, 9(4), 06-28.

Fadul, É., 2014). Administração pública no Brasil: reflexões sobre o campo de saber a partir da Divisão Acadêmica da Associação Nacional de Pós-Graduação e Pesquisa em Administração (2009-2013). Revista de Administração Pública, 48(5), 1329-1354.

Ferreira, M. P., \& Falaster, C. (2016). Uma análise comparativa dos fatores de rejeição nos periódicos de diferentes estratos de administração. RAC, 20(4), 412-433.

Freire, G. H. (2006). Ciência da informação: temática, histórias e fundamentos. Perspectivas em Ciência da Informação, 11(1), 6-19.

Judice, V. M. M., \& Baêta, A. M. C. (2005). Modelo empresarial, gestão de inovação e investimentos de venture capital em empresas de biotecnologia no Brasil. Revista de Administração Contemporânea, 9(1), 171-191. 
Leal, R. F. C., Almeida, V. S., \& Bortolon, P. M. (2013). Produção científica brasileira em finanças no período 2000-2010. Revista de Administração de Empresas, 53(1), 046-055.

Leite Filho, G. A. (2008). Padrőes de produtividade de autores em periódicos e congressos na área de contabilidade no Brasil: um estudo bibliométrico. RAC, 12((2), 533-554.

Lopes, A. B. (2004). A teoria dos contratos, governança corporativa e contabilidade. Local: Atlas.

Malacrida, M. J. C., \& Yamamoto, M. M. (2006). Governança corporativa: nível de evidenciação das informações e sua relação com a volatilidade das ações do Ibovespa. Revista Contabilidade e Finanças, 17, 65-79.

Mello, C. D., Crubellate, J. M., \& Rossoni, L. (2010). Dinâmica de relacionamento e prováveis respostas estratégicas de programas brasileiros de pós-graduação em administração à avaliação da capes: proposições institucionais a partir da análise de redes de coautorias. Revista de Administração Contemporânea, 14(3), 434-457.

Mendonça Neto, O. R., Riccio, E. L., \& Sakata, M. C. G. (2009). RAE, 49(1), 062-073.

Mendes-da-Silva, W., Onusic, L. M., \& Giglio, E. M. (2013). Rede de pesquisadores de finanças no Brasil: um mundo pequeno feito por poucos. RAC, 17(6), 739-763.

Nascimento, A. R., Junqueira, E., \& Martins, G. de A. Pesquisa acadêmica em contabilidade gerencial no Brasil: análise e reflexões sobre teorias, metodologias e paradigmas. Revista de Administração Contemporânea, 14(6), 1113-1133.

Nascimento, S., \& Beuren, I. M. (2011). Redes sociais na produção científica dos programas de pósgraduação de ciências contábeis do Brasil. RAC, 15(1), 47-66.

Oliveira, M. C. (2002). Análise dos periódicos brasileiros de contabilidade. Revista Contabilidade \& Finanças, 13(29), 68-86.

Parreiras, F. S., 2006). RedeCl: colaboração e produção científica em ciência da informação no Brasil. Perspectivas em Ciência da Informação, 11(3), 302-317.

Paula, M. M. de, (2012). Diálogo científico nos Congressos Anpcont: diversidade inovadora ou isomorfismo institucionalizado? Contabilidade, Gestão e Governança, 15, 35-51.

Pedroni, F. V., 2016). Pesquisa contábil, um estudo bibliométrico: identificação das publicações relevantes e análise da estrutura intelectual. RCC, 13(53), 53-91.

Ribeiro, H. C. M. (2013). Características da produção veiculada na Revista de Educação e Pesquisa em Contabilidade no período de 2007 a 2012. REPeC, 7(4), 424-443.

Ribeiro, H. C. M., \& Corrêa, R. (2017). Área temática controladoria e contabilidade gerencial: dez anos de sua produção científica divulgada no congresso Anpcont. In Anais, 6 Associação Nacional de Programas De Pós-Graduação em Ciências Contábeis.

Ribeiro, H. C. M., Costa, B. K., \& Ferreira, M. A. S. P. V. (2014). Produção acadêmica dos temas estratégia e governança corporativa. Revista de Administração FACES, 13(3), 27-46.

Ribeiro, H. C. M. (2015). Particularidades da produção acadêmica publicada na Revista de Administração e Contabilidade da Unisinos no período de 2004 a 2014. Contabilidade Vista \& Revista, 26(3), 80-105.

Ribeiro. H. C. M. (2014). Quinze anos de produção acadêmica do tema contabilidade internacional: uma análise bibliométrica em periódicos brasileiros. $\operatorname{REPeC}, 8(3), 326-343$.

Ribeiro, H. C. M., \& Santos, M. C. Perfil e evolução da produção científica do tema governança corporativa nos periódicos Qualis/Capes nacionais: uma análise bibliométrica e de redes sociais. Contabilidade, Gestão e Governança, 18(3), 04-27.

Ribeiro, H. C. M., \& Tavares, V. C. M. (2017). Comportamento e particularidades da produção acadêmica do tema "contabilidade gerencial" divulgada na base de dados do ISI WEB of Science Core Collection 
de 1985 a 2014. REPeC, 11(1), 5-29.

Rosa, A. F., (2010). Earnings management no Brasil: uma análise sob a perspectiva sociométrica e bibliométrica. Contabilidade Vista \& Revista, 21(4), 189-218.

Rossoni, L., Hocayen-da-Silva, A. J., \& Ferreira Júnior, I. (2008). Aspectos estruturais da cooperação entre pesquisadores no campo de administração pública e gestão social: análise das redes entre instituições no Brasil. Revista de Administração Pública, 42(6), 1041-1067.

Schweitzer, F. (2010). Produção científica em área de construção interdisciplinar: educação a distância no Brasil. (Dissertação de mestrado). Universidade Federal de Santa Catarina, Florianópolis,

Silva, H. A. S., (2012). Programas de pós-graduação em contabilidade: análise da produção científica e redes de colaboração. Revista de Contabilidade e Organizações, 6(14).

Silva, R. C. E. O., 2015). Análise de desempenho das ações das empresas do setor da construção civil na Bovespa em relação à rentabilidade, estrutura de capital e conjuntura setorial. Revista Catarinense da Ciência Contábil, 14(41), 09-19.

Souza, F. C., (2008). Análise das IES da área de Ciências Contábeis e de seus pesquisadores por meio de sua produção científica. Contabilidade Vista \& Revista, 19, 15-38.

Souza, F. J. V., Silva, M. C., \& Oliveira Araújo, A. (2013). Uma análise da produção científica da área de contabilidade governamental nos periódicos que utilizam o SEER e o SciELO. Revista de Contabilidade da UFBA, 7(2), 22-37.

Souza, M. T. S., (2013). Estudo bibliométrico de teses e dissertações em administração na dimensão ambiental da sustentabilidade. Revista Eletrônica de Administração, 76, 541-568.

Souza, M. T. S., \& Ribeiro, H. C. M. (2013). Sustentabilidade ambiental: uma meta-análise da produção brasileira em periódicos de administração. RAC, 17(3), 368-396.

Tesche, A. F., \& Souza, Â. R. (2016). Contabilidade de custos: uma análise bibliométrica dos estudos realizados nos congressos Enanpad e Anpcont de 2009 a 2014. ConTexto, 16(33).

Theóphilo, C. R., \& ludícibus, S. (2005). Uma análise crítico-epistemológica da produção científica em contabilidade no Brasil. Contabilidade, Gestão e Governança, 8(2), 147-175. 